\title{
SOBRE UNA ESCULTURA OLMECA RECIENTEMENTE ENCONTRADA EN LA VENTA, TABASCO *
}

\section{Por Beatriz de la Fuente}

Una vez más nos enteramos de que nuestras ciudades arqueológicas son constantemente acechadas por los saqueadores; muchas veces el saqueo es consumado; otras, las menos, los hechos llegan a conocimiento de las autoridades y, en muy raras ocasiones, se impide su realización. En este último caso se encuentra una excepcional escultura olmeca, cuyo robo fue impedido momentos después de que subrepticiamente se la habia desenterrado. Con ello se evitó que fuera a enriquecer alguna colección particular, o que pasara a formar parte de la sección de "arte primitivo" de algún museo del extranjero.

La pieza en cuestión es en verdad interesante, no sólo por su alta calidad artística, en la cual se conjugan clásicos elementos formales y expresivos, sino porque en ella se integran elementos simbólicos de gran significación en la imaginería olmeca. Es así como esta pieza, además de su relevante carácter de unicidad artística, resulta un eslabón de indudable importancia en la cadena de esculturas monumentales que une, de manera cercana, los estilos de los dos grandes centros olmecas: La Venta y San Lorenzo.

Gracias a la información que gentilmente me proporcionó el arqueólogo Eduardo Contreras, tuve conocimiento de cómo a causa de la voz de alarma de un guardián de la zona arqueológica se frustró el saqueo. La escultura estaba ya a bordo de una camioneta que por cierto se encontraba muy próxima a la hondura de donde la extrajeron, la cual tenía una profundidad de entre 160 y $180 \mathrm{~cm}$ y estaba situada al norte muy cerca de la Gran Pirámide en el Complejo A.

En la actualidad se encuentra sobre una base de piedra enfrente de la Presidencia Municipal de La Venta. El lugar, si bien es el de su origen, no es, desafortunadamente el que hoy le corresponde. Es de todos conocido que Ia Venta es un sitio petrolero en donde se da poca importancia a la vida del pasado; en donde no hay, me parece, el respeto o amor debidos a lo que otros consideramos parte de nuestro más preciado patrimonio. Y, aquí entre la actividad de las refinerías, se encuentra sin pro-

- Agradezco al arqueólogo Eduardo Contreras del INAH el haberme proporcio. nado las fotografias que aquí se publican. 
tección un de las más hermosas tallas olmecas. No sé quiénes hayan decidido su colocación, pero tengo la certeza de que lo hicieron movidos por la ignorancia, o tal vez tan sólo por la indiferencia. De cualquier manera, si es aquí en donde va a permanecer, aun en el caso de que no sea destruida o robada, se verá muy pronto señalada por la huella irreparable de la intemperie, huella que al cabo de unos años se convertirá en deterioro semejante al que han sufrido las monumentales esculturas del Parque-Museo de Villahermosa, hermanas de ésta en origen y en destino.

Al igual que otras esculturas de La Venta, la que hoy me ocupa está tallada en basalto olivino color café, procedente de las montañas de Los Tuxtlas. Sus dimensiones son $113 \mathrm{~cm}$ de alto total por el frente,y 110 por la parte de atrás; tiene $96 \mathrm{~cm}$ de ancho máximo a nivel de las piernas, 84 de espesor en la base, y pesa $750 \mathrm{~kg}$. Se conserva un muy buenas condiciones; la erosión que ha sufrido se muestra principalmente en pequeños hoyos esparcidos por toda su superficie, y en el desgaste de la boca; las fracturas al frente de la parte superior del tocado, de la ban$\mathrm{da}$, de la nariz y de los dedos de ámbos pies, parecen recientes debido a! distinto tono en el color de la piedra. De acuerdo con la catalogación establecida ${ }^{1}$ y $^{2}$ le corresponde el número 77 entre los monumentos de La Venta.

En algún otro lugar ${ }^{3}$ he asentado que son tres los grandes conjuntos en que pueden agruparse las esculturas monumentales olmecas, tomando como base lo que en ellos se reconoce visualmente; es así como entre ellas encuentro figuras compuestas o híbridas, figuras humanas y figuras animales. El Monumento 77 de la Venta es la única de todas las esculturas olmecas conocidas que, a pesar de su apariencia humana, debe quedar incluida dentro del conjunto de figuras compuestas. Combina en una sola imagen rasgos simbólicos propios de las figuras que no tienen modelo natural, con el aspecto propiamente humano, de tal suerte que es licito suponer que no pretende reproducir lo existente en la naturaleza; al ir más allá de lo meramente perceptible, lo expresado por medio

1 Clewlow, C. W. Jr. y C. R. Corson. "New Stone Monuments from La Venta," 1968. 1968 Investigations at La Venta. Contributions of the University of California Archaeological Research Facility, núm. 5. Appendix II, Berkeley, California, pp. 171-202.

2 De la Fuente, Beatriz. Escultura monumental olmeca. Catálogo. Instituto de Investigaciones Estéticas, UNAM. México, 1973.

3 De la Fuente, Beatriz. San Lorenzo y La Venta. Escultura monumental. Tesis inédita de Doctorado en Historia. Facultad de Filosofía y Letras, UNAM, México, 1974, p. 131. 
de la realidad plástica, es un concepto. No se trata, en suma, de una copia, sino de una entidad fantástica, imaginada, constituida por elementos y formas reconocibles que se funden con otros abstractos y simbólicos. Por otra parte, su aspecto donde se combinan rasgos tan cercanamente relacionados con la convencional imaginería olmeca, le otorga carácter sobrenatural.

Su configuración revela, como ocurre con frecuencia en las grandes tallas olmecas, que se procura mantener en ella una armonia geométrica; por ello tanto vista de frente (figura 1) como de perfil (figura 2) se aprecia que la forma total de la pieza queda inscrita dentro de una pirámide de planta rectangular y vértice superior trunco. Por otra parte, sus volúmenes redondeados y compactos, su pesantez y el sintetismo de los rasgos corporales, acusan también la voluntad de forma característica de estas esculturas.

La cabeza es un cubo que remata por arriba en un tocado compuesto de varias secciones, y el rostro es un cuadrado de ángulos redondeados (figura 3). Las facciones, discretamente modeladas, son las de un niño, similares a las de muchos otros semblantes olmecas. No son rasgos que muestren individualidad, ya que con ellos no se trata de destacar algo particular sino de repetir un esquema. La cara se mira, como en tantas más, imperturbable; no se busca representar la expresión singular; se mantiene un arquetipo.

Los ojos son ovales con las comisuras internas apuntadas; los globos oculares aplanados llevan iris realzados ligeramente. La proyección del borde de éstos delimita los ojos y los agranda visualmente; así, a pesar del notable abultamiento de los párpados, no se ven entrecerrados, como sucede en otras representaciones. Es evidente que se trata de ojos humanos, supuesto que guardan disposición horizontal; los ojos animales, en especial los del felino, se figuran siempre oblicuos.

Aunque quebrada en la punta, aún se aprecia que la nariz se unía directamente con el labio superior, ahora mutilado, la boca entreabierta deja asomar la encia superior, los gruesos labios se proyectan hacia afuera, y las comisuras se contraen hacia abajo. Es la conocida boca olmeca, arbitrariamente designada como "boca de jaguar" por el solo hecho de que sus extremos se curvan hacia abajo. Cuelga la carnosidad de las mejillas, y el mentón es una protuberancia redondeada. Se trata, en fin, del rostro que los arqueólogos han llamado baby face y que delata, conjuntamente con otros signos y atributos, la naturaleza de la figura representada. 
Además de la semejanza que mantiene con numerosas piezas de menor tamaño, encuentro en el rostro de ésta un gran parecido con los de los Monumentos 44 de La Venta y 1 de San Martín Pajapan (figura 4) y, en menor grado, con "El Príncipe" de Cruz del Milagro y la escultura de Cuauhtotolapan Viejo. A todos los relaciona la apariencia infantil.

Por otra parte, es frecuente que este tipo de rostros vayan unidos a cuerpos robustos, reciamente constituidos; el Monumento 77 de La Venta no escapa a tal característica. La posición sedente, con las piernas cruzadas a la manera oriental, es también común a estas figuraciones y muy usual en la estatuaria olmeca; asi se representaron muchas de las figuras que emergen de las cuevas de los "altares", y así se miran otras esculturas como los Monumentos 8, 9, 10, 23 y 30 de La Venta y 11, 12 y 47 de San Lorenzo. Quiero señalar especialmente la particular similitud, no sólo en la posición, sino en el tratamiento sensual de las formas corporales, que la pieza en que ahora me ocupo guarda con los monumentos 23 de La Venta y 47 de San Lorenzo.

La posición sedente con las piernas cruzadas, favorece la apariencia de pesantez que emana del Monumento 77, aun cuando hay que considerar que las formas del cuerpo son en sí también volúmenes pesados. El cuerpo obeso, de apretada carnosidad, se une con la cabeza por medio de ese cuello corto y vigoroso que, por tales características Covarrubias designó como "cuello de toro". " Las piernas son un tanto voluminosas y los brazos, como gruesos rollos compactos, se doblan adheridos contra el cuerpo.

De igual modo que en otras esculturas de La Venta -Monumentos 9 y $10-$ y de San Lorenzo - Monumento 12-, los muslos se extiendan hacia el frente, como una plataforma que se proyecta y sirve de asiento al cuerpo de la figura; las piernas son cónicas y terminan en pies curiosamente representados, la planta sigue la misma dirección del eje de la pierna, y al frente, el dorso, escuetamente figurado, carece del quiebre del tobillo. Se trata de una solución plástica convencional, pues de hecho tal postura es imposible de lograr en la realidad.

Los brazos, de contornos suavemente ondulados, se continúan, contraparte formal de las piernas, con rígidos y esquemáticos antebrazos que terminan en puños cerrados. A pesar de que los brazos resultan muy cortos en relación con las piernas, se aprecia en ellos mayor expresividad; la tensión que revelan bajo los músculos contraídos, concuerda con

4 Covarrubias, Miguel. Arte indigena de México y Centroamérica. Trad. Sol Arguedas, UNAM, México, 1961, p. 64. 
la del rostro y contrasta, a su vez, con la falta de consistencia del resto del cuerpo. Es allí, en esas soluciones expresivas de rostro y brazos, acaso un tanto ásperas, donde se percibe la animación de la figura: algo así como control de impulsos, como dominio de emociones, en suma, como supremacía del espiritu sobre el cuerpo. La mano que se aprieta o la boca que se contrae, son el recurso, que, aunque por repetido se haya convertido en patrón expresivo-formal, también procura, y logra, comunicar el hondo sentido de aplomo, de dignidad y de firme autoridad que la imagen reúne.

Las características físicas, netamente humanas, a pesar de que se manifiestan en rasgos convencionales, definen el carácter no terrenal de la figura; su cara aniñada de mirada ausente y su cuerpo rechoncho corresponden a cierto tipo de efigies de carácter sobrenatural. No hay individualidad, insisto, ni se aprecia deseo alguno de mostrar aspectos que singularicen su persona. Reconozco, ya lo dije también, una serie de elementos comunes a la estatuaria olmeca y veo, una vez más repetido un esquema figurativo que delata la identidad de un conjunto escultórico. Es, en resolución en cuanto a la imagen representada, una de las que guardan, bajo su aspecto humano, profundas significaciones sobrenaturales. Ahora bien, si lo que la figura representa y significa no es novedoso, los recursos formales por medio de los cuales tal identidad cobra vida, si son certeramente renovados.

El Monumento 77 de La Venta concentra en el frente gran parte de su interés formal (figura 1). Es allf donde destaca la proyección del rígido bloque que constituyen el rostro y el tocado; donde la superficie remetida del cuerpo se muestra flexible y ondulante, y donde, por medio de la simulada plataforma de las piernas, se define el aplomo y la pesantez de la figura. Éste, discretamente dinámico juego de superficies que se proyectan y se remeten y de luces que contrastan, se ve formalmente aquietado en la parte posterior por la amplia capa que cubre toda la espalda.

En su vista trasera, las formas geométricas del tocado contrastan con las superficies ondulantes de la cabeza y la espalda (figura 5). Por abajo de la banda del tocado, el rehundimiento de la nuca se cubre con mechones de cabello que cuelgan sobre la espalda, y en cuyo centro resalta un elemento sobrepuesto de difícil apreciación (según Contreras, se trata de una pequeña cabeza invertida). La superficie cóncava de la nuca y el cuello se convierte, suavemente, en el manto que se desprende desde los hombros, y por cuya curvatura convexa son recogidos los ras- 
gos corporales del frente. Surcan la capa o manto bandas horizontales paralelas y un diseño alterno formado, al parecer, por nudos y por una franja que se bifurca en su parte superior. Es evidente, aun cuando no me sea posible precisar su identidad, que los diseños de la capa y el elemento sobrepuesto en ella, son signos que tienden a hacer reconocible la imagen.

Las soluciones formales del Monumento 77 son muy semejantes a las de los Monumentos 11 -"El Escriba"- y 47 de San Lorenzo (figura 6) que responden al patrón en donde la aquietada parte posterior recoge los elementos dinámicos de la anterior. Los dos se encuentran, desafortunadamente, decapitados; pero es posible suponer, con base en las semejanzas que guardan con otras esculturas como "El Príncipe" de Cruz del Milagro y, en particular, el Monumento 77 de La Venta, que tuvieran cabezas humanas $e$, inclusive, de rasgos infantiles.

De la evaluación formal del Monumento 77 de La Venta parece legítimo deducir una muy estrecha relación con algunas esculturas de San Lorenzo; en efecto comparte con ellas algunas características propias del estilo de dicho sitio en un momento determinado, aquel en el cual el estilo, ya maduro, ha establecido sus cualidades básicas que son el sentido del volumen, la estructura de cuerpos geométricos, la pesantez de la masa, el carácter de arraigo a la tierra, la monumentalidad, el ritmo interno de la forma cerrada, las superficies redondeadas $y$, sobre todo, la relación armónica de la proporción áurea. La mayor parte de las esculturas de San Lorenzo, incluyendo a todas las Cabezas Colosales, participan de estas cualidades, pero tengo para mí, que tal momento de auge en la escultura de San Lorenzo, no es el inicial, sino que se ha alcanzado después de haber experimentado diferentes caminos, algunos de los cuales desembocaron ante una puerta cerrada.

Por otra parte no encuentro, en el aspecto formal, ninguna escultura de La Venta equiparable al Monumento 77. Me refiero, en particular, a la integración perfecta del orden armónico con la unívoca organización formal. Hay, ciertamente, similitudes con otras; así, el muy destruido Monumento 23 muestra paralela calidad orgánica en las formas, y cosa semejante ocurre con las figuras sedentes de los "altares"; pero una muy distinta conciencia formal emana de los Monumentos 8, 9 y 10, con los cuales el 77 parece a primera vista tener semejanza. La diferencia principal entre las monumentales figuras sedentes de San Lorenzo y de La Venta, es que en estas últimas el volumen se ve penetrado por el espacio produciendo, a pesar de su monumentalidad, efectos de lige- 
reza y de desprendimiento, mismos que en ocasiones se ven incrementados por el desplazamiento de las formas hacia el exterior. Ahora bien, estas cualidades no se aprecian en el Monumento 77 , en tanto que destacan las que caracterizan al estilo de San Lorenzo. Lo anterior me permite suponer no sólo una comunicación cercana entre ambos centros olmecas sino la coexistencia temporal de los mismos. No creo necesariamente admisible que, como se ha dicho con base en las fechas proporcionadas por el radiocarbono, La Venta haya sucedido en tiempo a San Lorenzo; me parece, más bien, que la ocupación de las dos ciudades fue simultánea, y que dentro de una misma tradición cultural, la olmeca, cada una se manifestó en su arte con individualidad.

EI carácter simbólico de la figura se ve reforzado por signos en el vestuario, en los ornamentos y en el tocado; todos deben ser considera. dos para obtener su cabal identidad. El torso está ceñido por una banda ancha seccionada en cinco franjas, que lleva al centro a manera de hebilla un cuadrete rematado, por arriba y por abajo, con cuatro triángulos; en su interior se miran simbólicas bandas cruzadas. Sobre las adiposas tetillas, cuelga un pectoral, marco rectangular para dos bandas cruzadas, que se relaciona armónica y significativamente con el símbolo del ceñidor. En otra escultura olmeca, el niño del "Señor de las Limas", se conjugan los dos diseños de la misma manera (figura 7), en tanto que en los Monumentos 30 de La Venta y 52 de San Lorenzo, se encuentra tan solo el pectoral. Bandas cruzadas se ven asimismo ocupando el cuerpo de una extraña figura: el pez felino, Monumento 58, de San Lorenzo. Las bandas cruzadas, ya lo han hecho notar $\operatorname{Coe}^{5}$ y Joralemon, ${ }^{6}$ son simbolo recurrente en la iconografía olmeca, y está evidentemente asociado con las figuras compuestas, las imágenes fantástico-humano-felinas, y evoca de seguro algún aspecto importante de su sentido profundo. No es, sin embargo, fácil de precisar si el sitio en el cual aparece, que puede ser muy variado, los ojos, el pecho, el ceñidor, etcétera, indica alguna cualidad particular de la imagen.

Otro elemento puesto para dar carácter a la imagen es el tocado Constituido por una banda horizontal que resalta al frente como ala de sombrero, y se ajusta al cráneo por la parte de atrás, muestra estrías

6 Coe, M. D. "The Olmec Style and its Distribution" en Handbook of Middle American Indiana, vol. 3, Part two, pp. 739-775. University of Texas Press, Austin, Texas, 1965, p. 761.

6 Joralemon, D. "A Study of Olmec Iconography." Studies in Pre-Columbian Art and Archaeology, núm. 7, Dumbarton Oaks Research Library and Collection, Washington, D. C., 1971, pp. 30-31. 
verticales y remata al frente en un elemento hoy mutilado, en donde aún se distinguen cuatro protuberancias que recuerdan los dedos de una mano o garra (figura 3). Por la parte posterior, la banda es remetida, y bajo ella, lo he dicho ya, cae la cabellera en mechones. La parte superior del tocado es como un prisma rectangular que se proyecta hacia atrás y cuyo extremo se divide en cuatro por la intersección de dos acanaladuras que se estrechan hacia su parte central; en las superficies laterales de dicho prisma, se miran cinco discos en relieve. Es evidente que la parte anterior fue rota hace no mucho tiempo; la parte faltante tal vez haya sido de interés primordial. Lo que se conserva es, de cualquier modo, sugerente en cuanto a la naturaleza de la figura, ya que esa parte prismática dividida en su extremo en cuatro secciones, es igual a la que define los tocados de los Monumentos 44 de La Venta y 1 de San Martín Pajapan (figura 8). Dado que éstos llevan al frente una máscara humanofelina de ojos almendrados y oblicuos, nariz chata y amplia y boca grande con gruesos labios arqueados, parece legítimo suponer que la sección que le falta al Monumento 77 pudiera haber sido una máscara semejante, y que todos participaran de la misma condición de representar algo sobrenatural.

Aun cuando hay diferencias entre el Monumento 44 de La Venta y el ídolo de San Martín Pajapan, 7 se trata en ambos casos de la representación de la misma imagen, y el estilo, abigarrado en sus formas y burdo en su fábrica, es coincidente. No ocurre lo mismo con este Monumento 76, en que la talla más cuidadosa configuró una imagen mejor constituida que destaca nítidamente, pues en ella los numerosos elementos del tocado fueron sintetizados al máximo. Si bien supongo que, como en las esculturas 44 de La Venta y 1 de San Martín Pajapan, la que ahora analizo llevaba una máscara en la parte frontal del tocado, es seguro que no ocurría lo mismo con los diseños de la banda, con las estrías laterales, con la cimera y con las cabecitas que a manera de orejeras se encuentran en aquéllas. Tales elementos fueron anulados, y se conservó solamente lo que para evocar el significado requerido, se tuvo por esencial. Es ahora conveniente señalar que en la plástica olmeca hay diversas maneras de representación de lo que desde hace tiempo se ha llamado cabeza hendida; he de aclarar, por lo demás, que no considero que el tocado del Monumento 77 de La Venta y los de

7 Clewlow, C. W. Jr. "Comparación de dos extraordinarios monumentos olmecas." Boletin del Instituto Nacional de Antropología e Historia, núm. 34. México 1968, pp. 37.41. 
DOI: http://dx.doi.org/10.22201/iie.18703062e.1976.45.1034

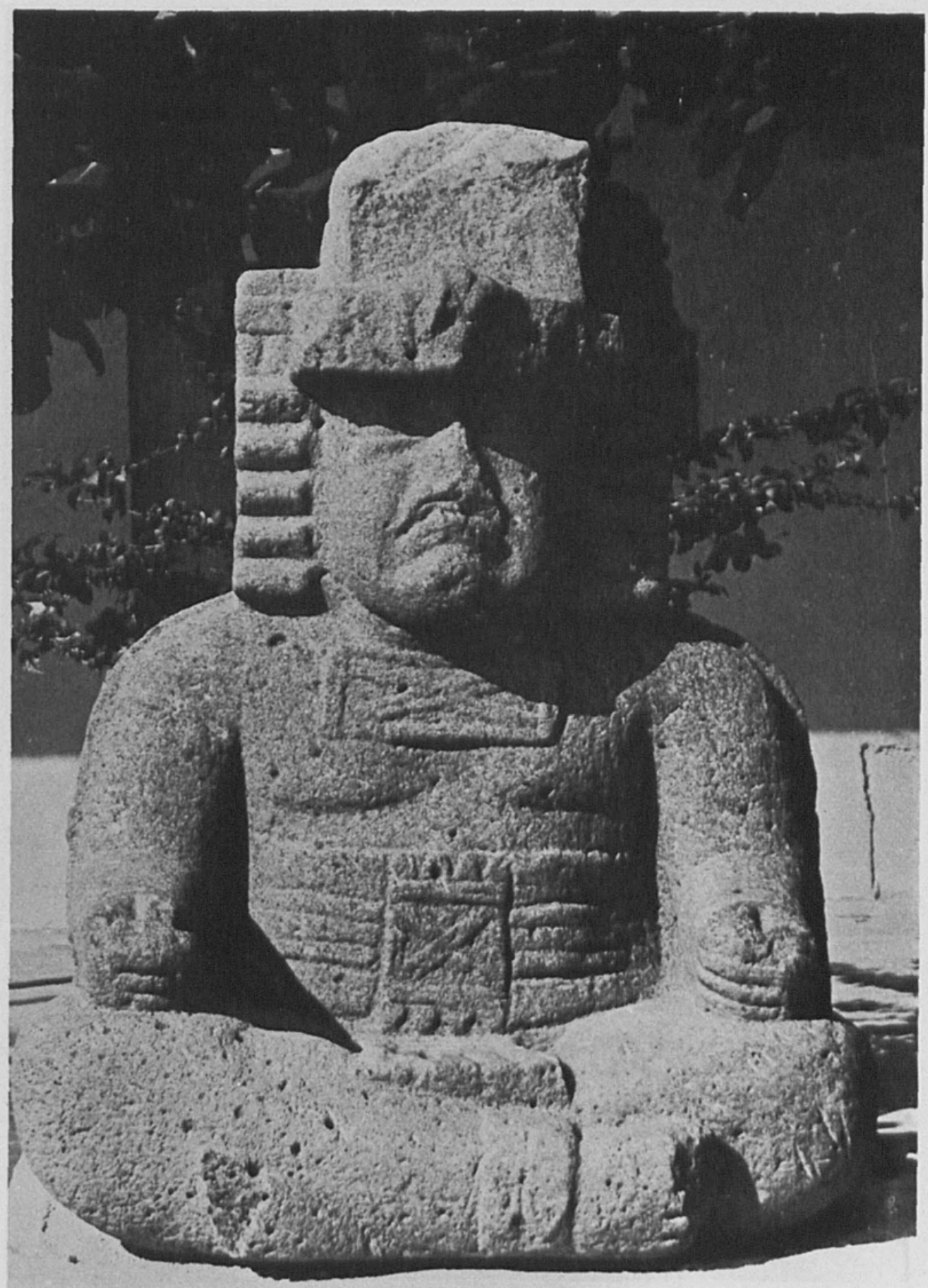

1. Monumento 77 de La Venta (frente). 
DOI: http://dx.doi.org/10.22201/iie.18703062e.1976.45.1034

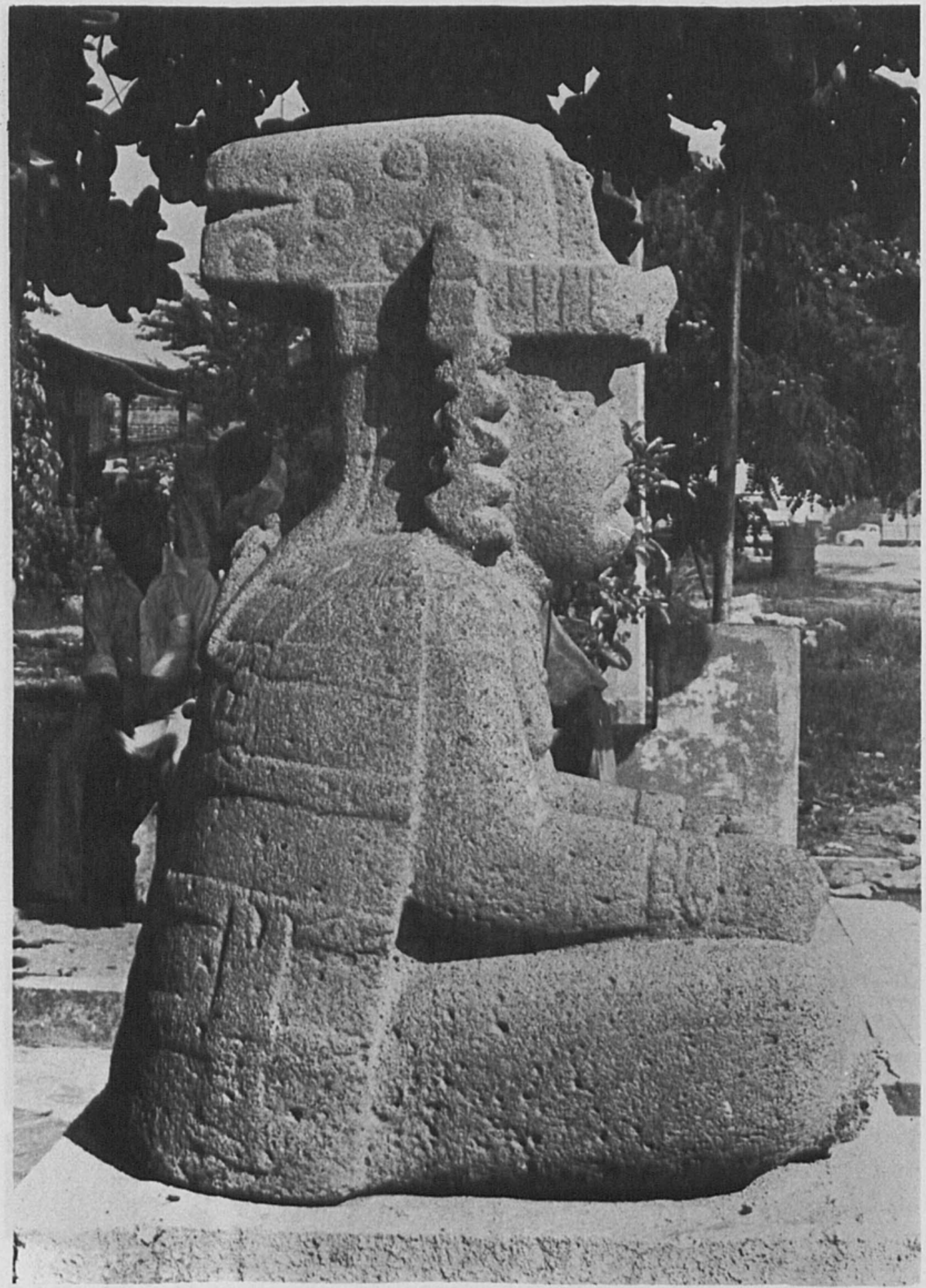

2. Monumento 77 de La Venta (perfil). 
DOI: http://dx.doi.org/10.22201/iie.18703062e.1976.45.1034

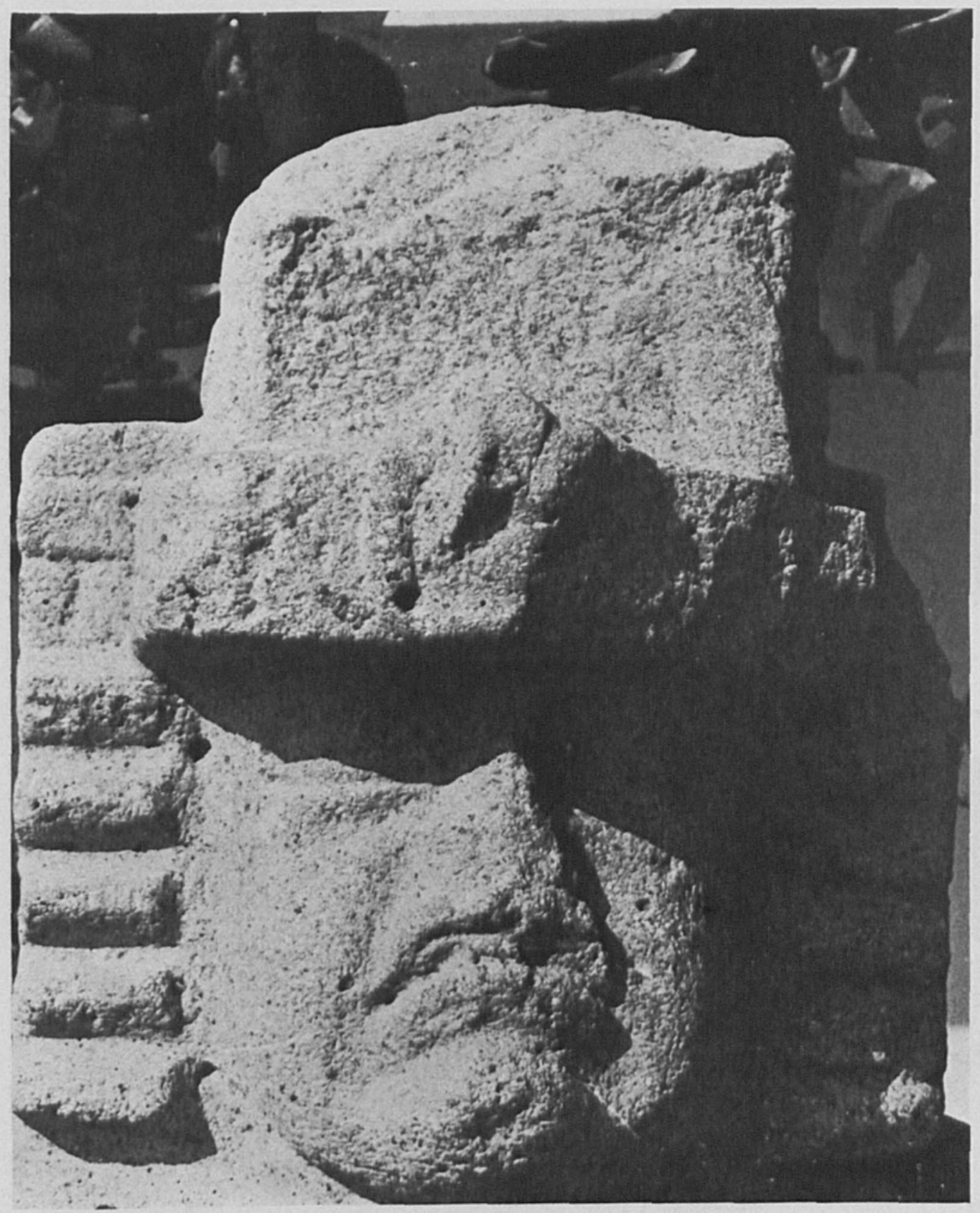

3. Monumento 77 de La Venta (detalle de la cabeza y del tocado). 
DOI: http://dx.doi.org/10.22201/iie.18703062e.1976.45.1034

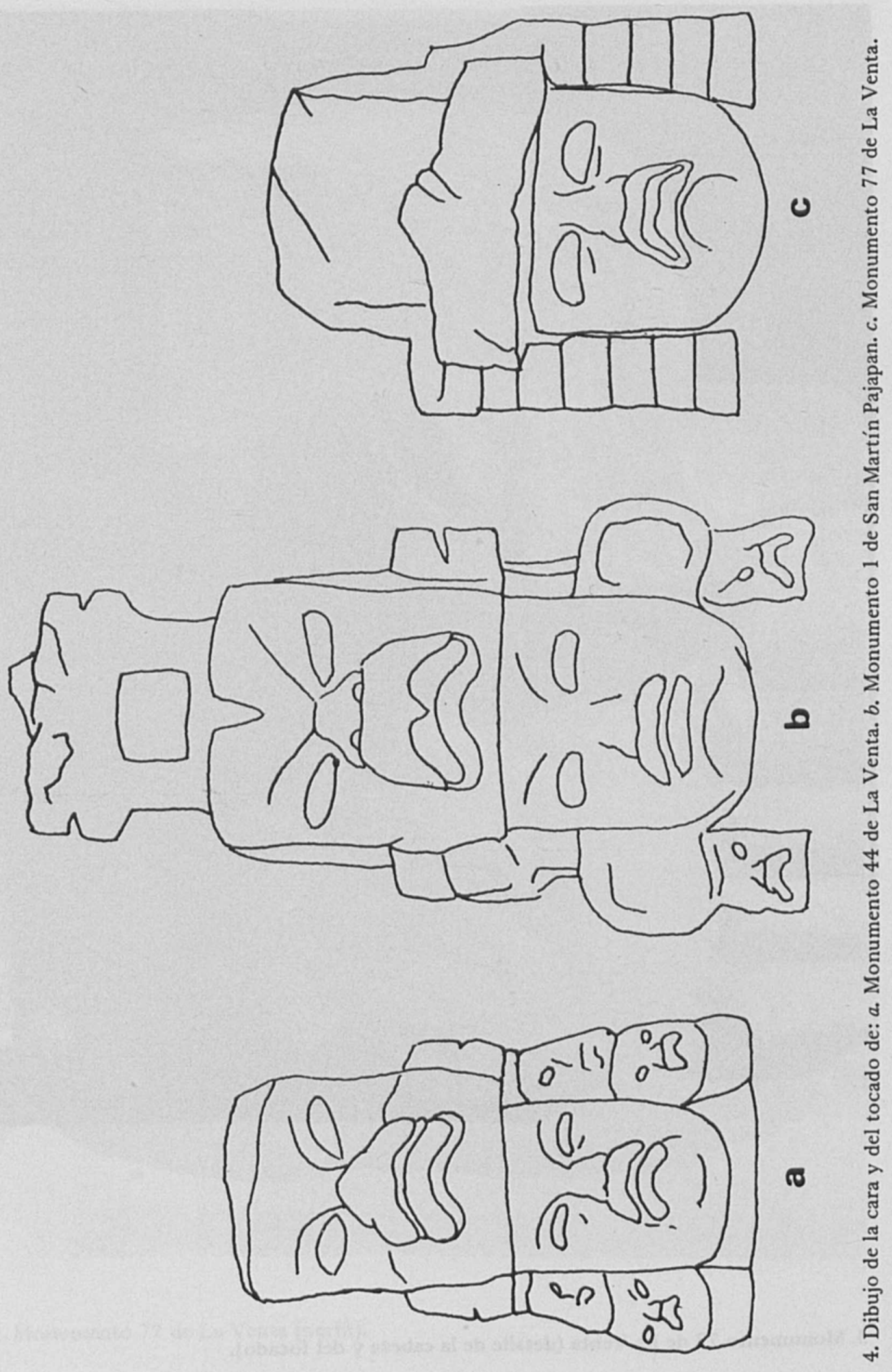


DOI: http://dx.doi.org/10.22201/iie.18703062e.1976.45.1034

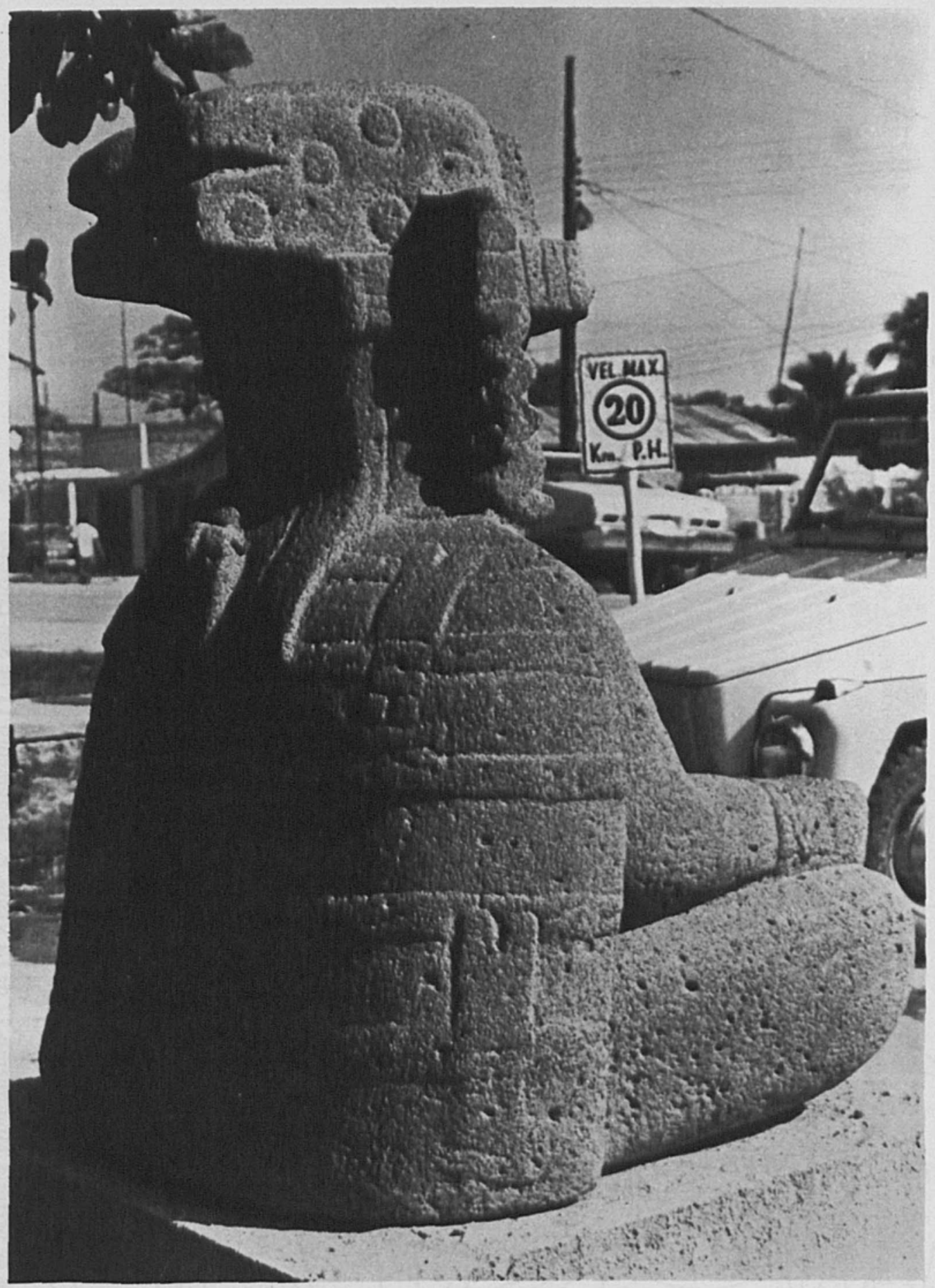

5. Monumento 77 de La Venta (vista posterior). 


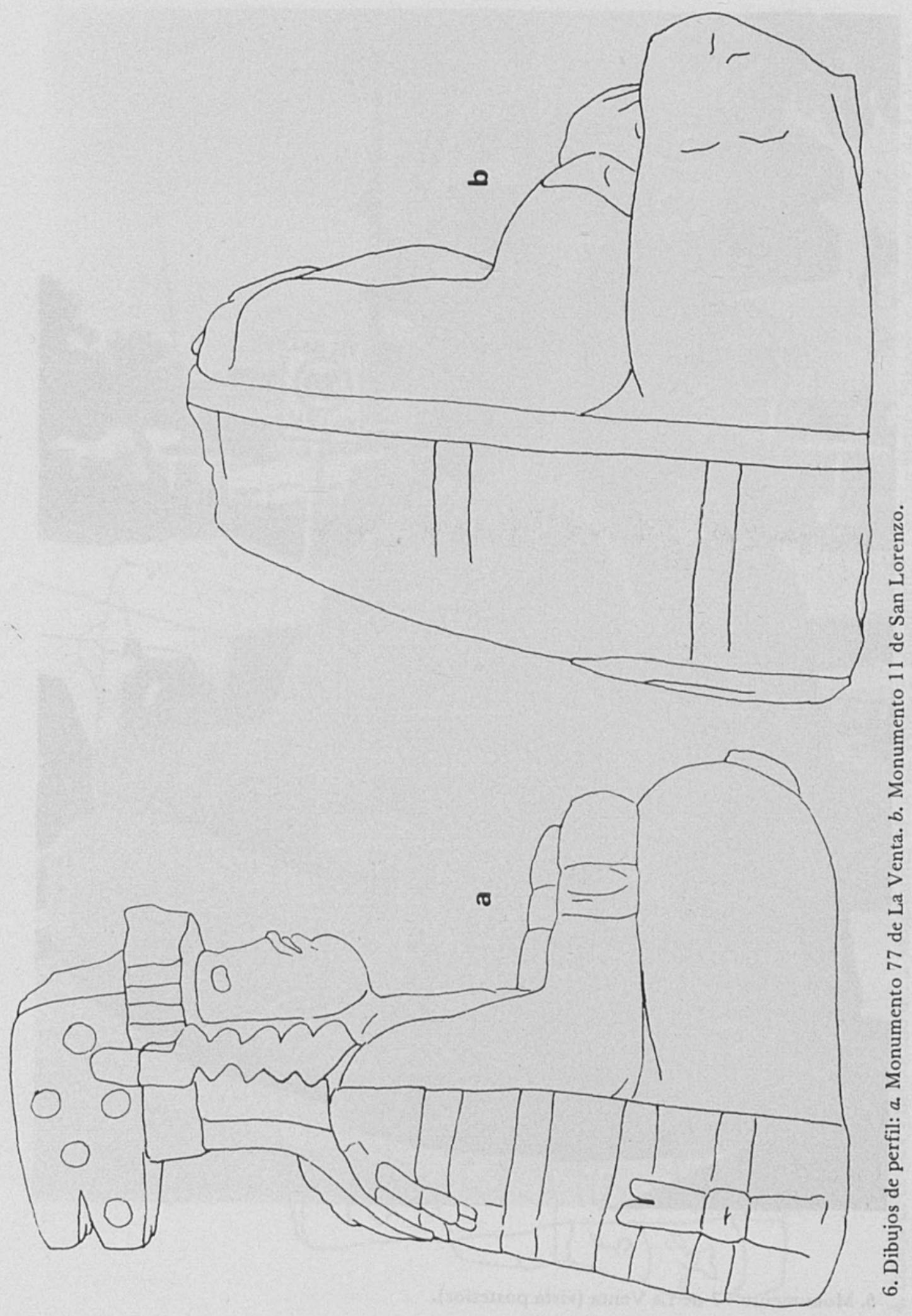


DOI: http://dx.doi.org/10.22201/iie.18703062e.1976.45.1034

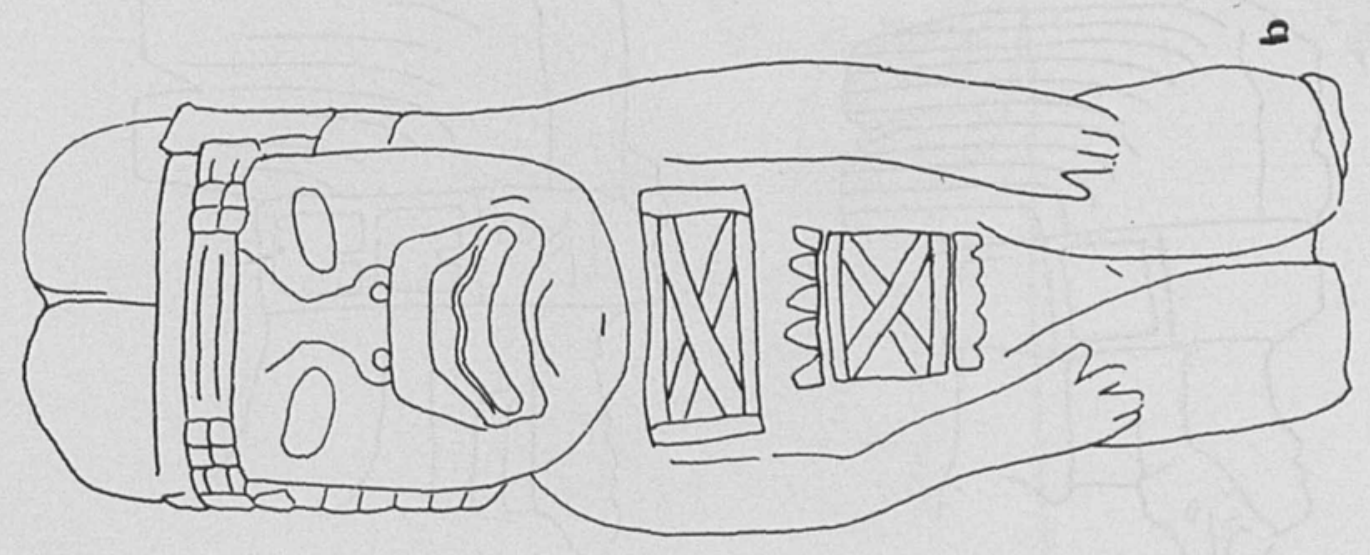

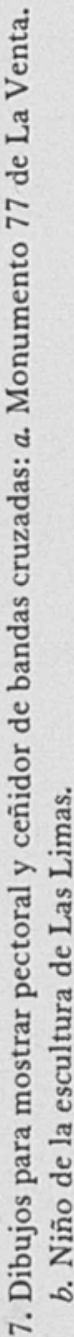



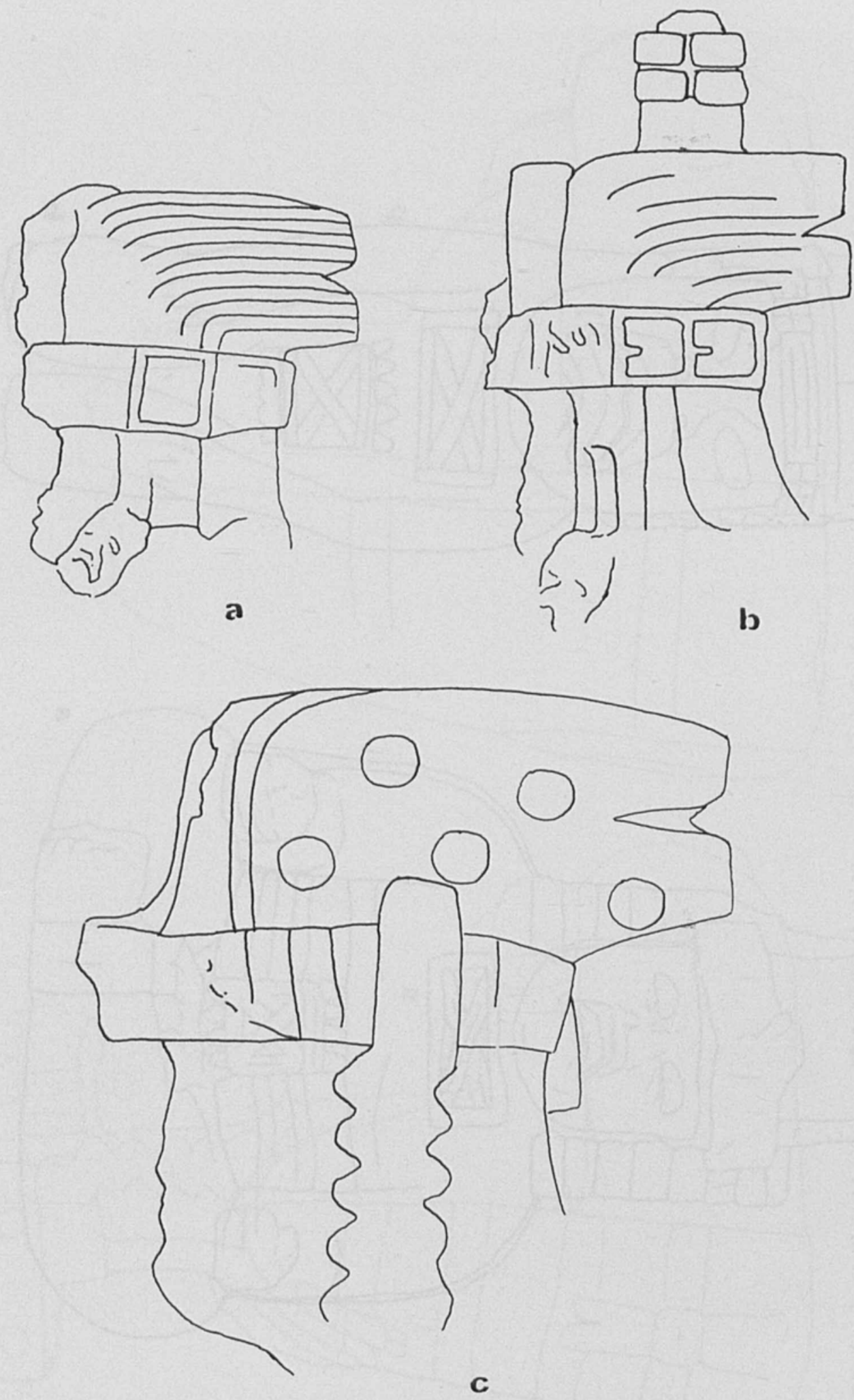

8. Dibujos de tocados vistos de perfil: $a$. Monumento 44 de La Venta.

b. Monumento 1 de San Martín Pajapan. c. Monumento 77 de La Venta. 

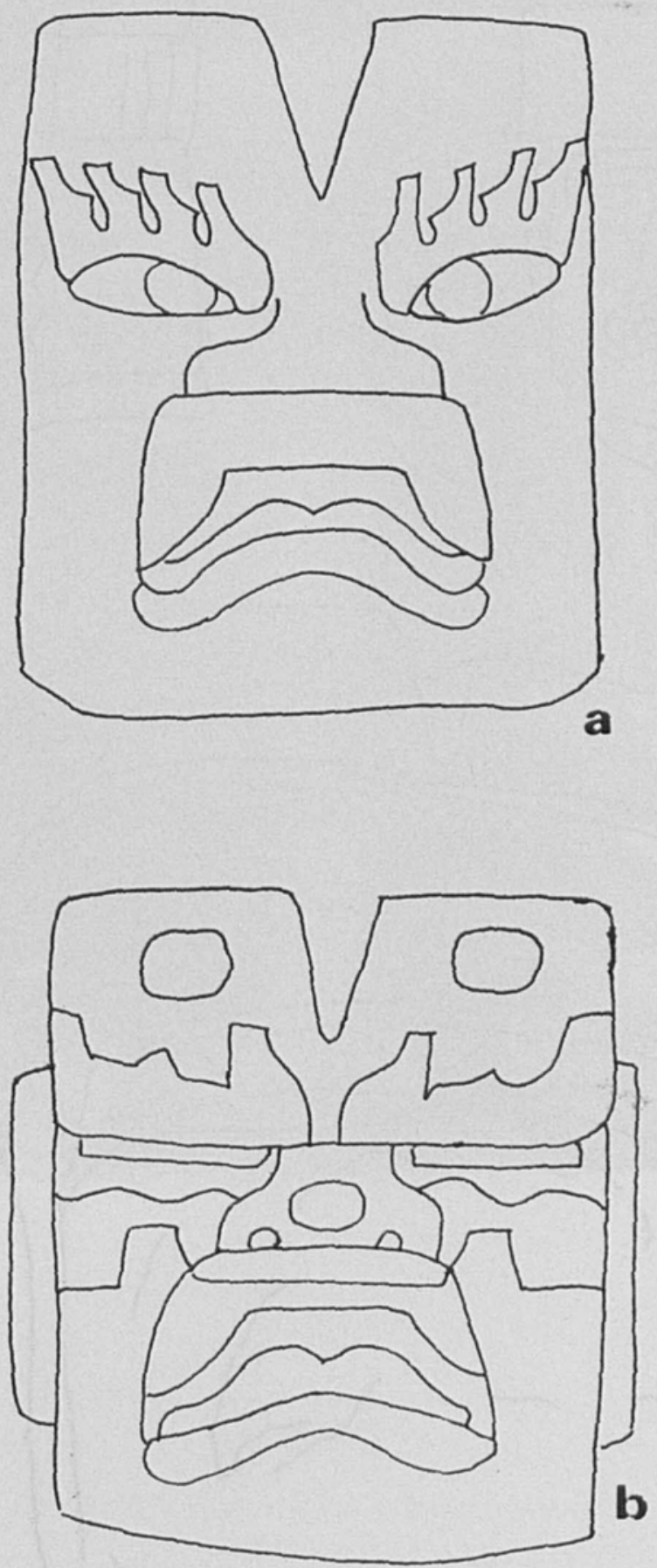

9. Dibujos de cabezas de hachas (según Joralemon). a. Hacha de la Mixteca.

b. Hacha de Oaxaca. 
DOI: http://dx.doi.org/10.22201/iie.18703062e.1976.45.1034
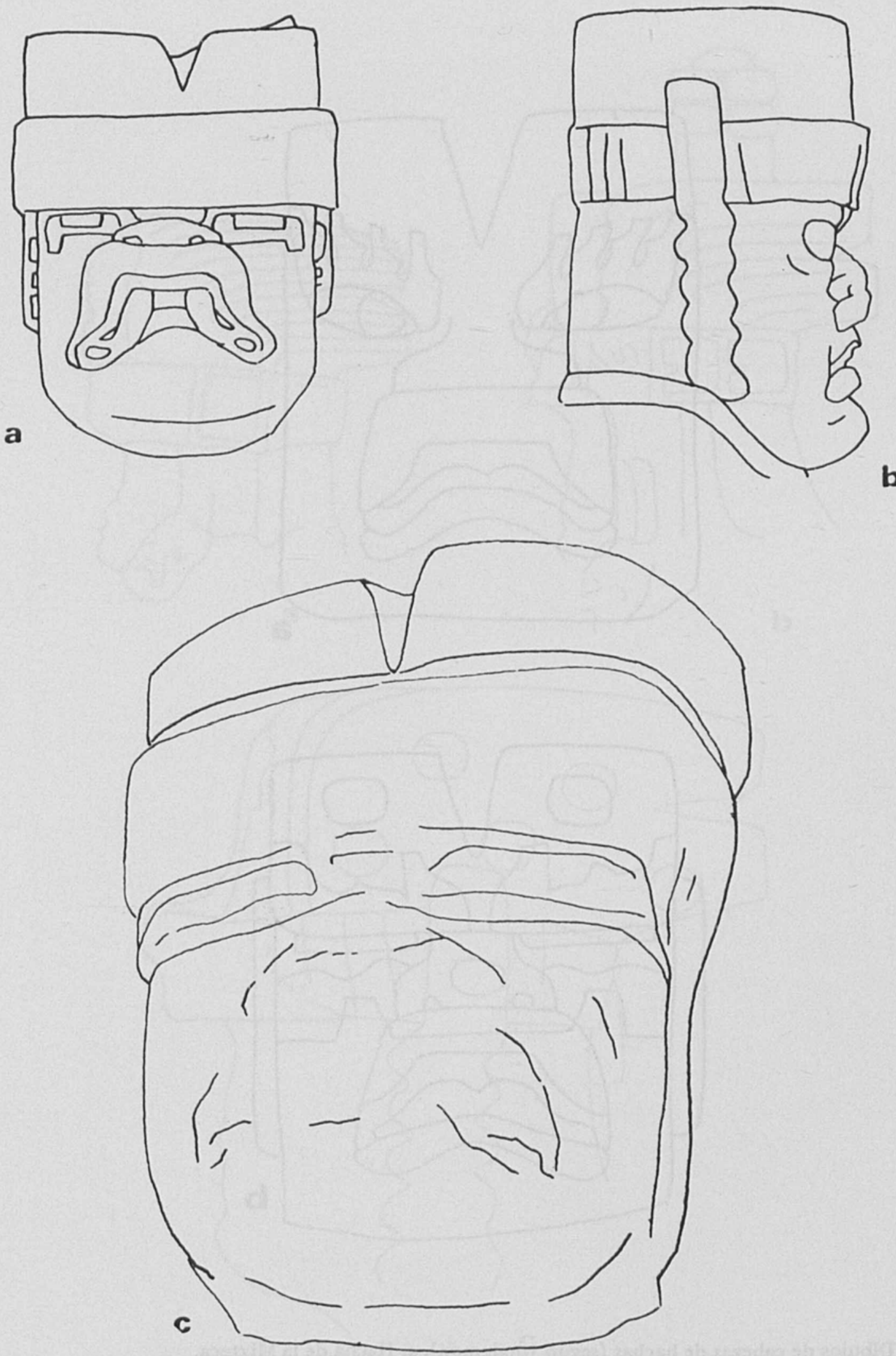

10. Dibujos de cabezas de: $a$. Monumento 10 de San Lorenzo. $b$. Monumento 52 de San Lorenzo. c. Monumento 64 de La Venta. 
DOI: http://dx.doi.org/10.22201/iie.18703062e.1976.45.1034

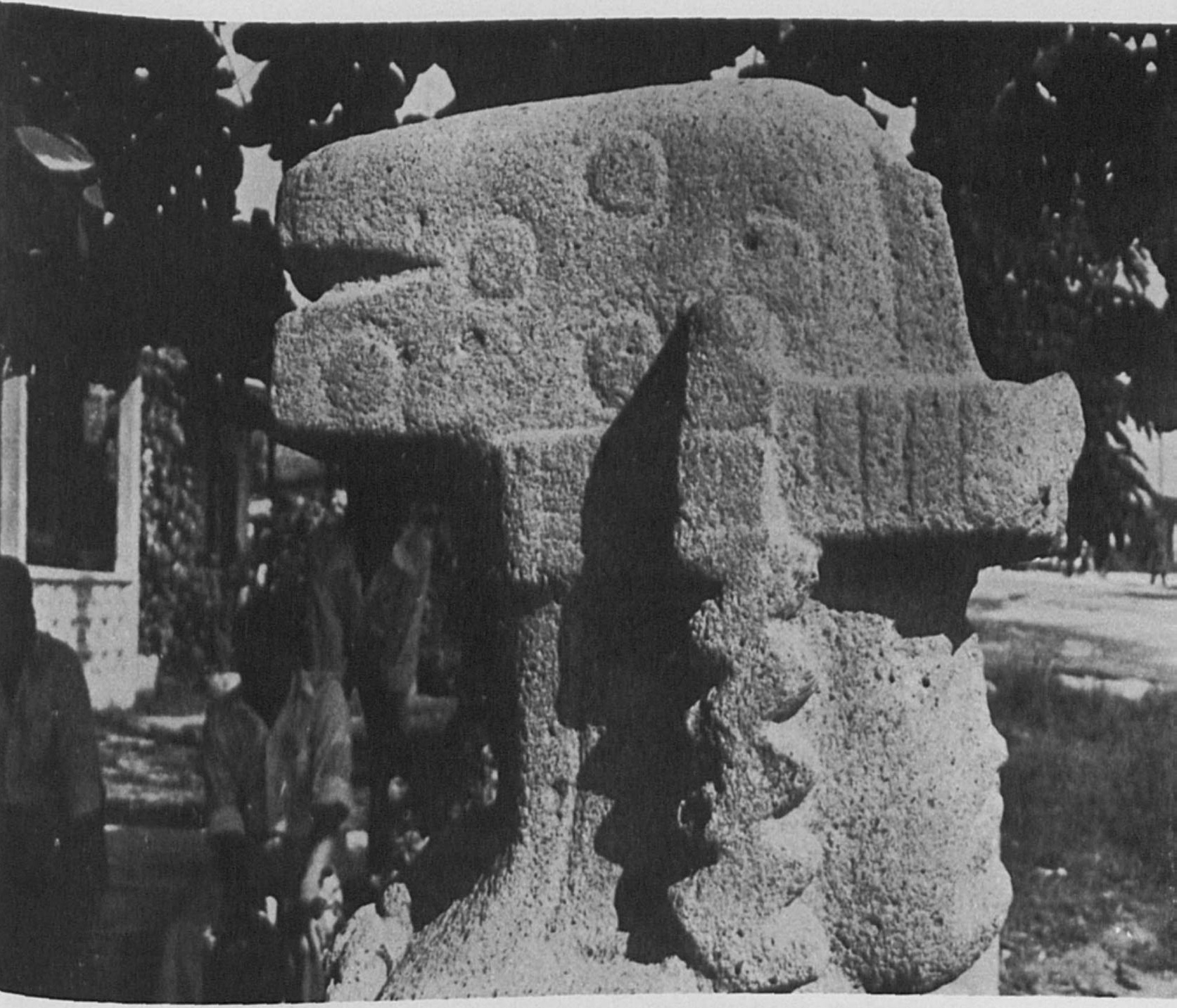

11. Monumento 77 de La Venta (detalle del perfil de la cabeza y el tocado). 
DOI: http://dx.doi.org/10.22201/iie.18703062e.1976.45.1034 
aquellos que le son tan parecidos, los de los ya varias veces mencionados Monumentos 44 del mismo lugar y l de San Martin Pajapan, representen precisamente cabezas hendidas.

Este rasgo, que fue de los primeros que se hicieron notar como propios de las representaciones olmecas ${ }^{8} \mathbf{y}^{9}$ por su constancia en las pequeñas hachas de jade, se aprecia como una abertura en forma de $\mathrm{V}$, en el centro de la frente y por arriba del entrecejo (figura 9). Se ha dicho que representa "la mollera o fontanela bregmática de los recién nacidos" 10 o la "Spina bifida... que resulta en individuos que no han nacido con el cráneo abierto, y a menudo con rostros gruñidores y de aspecto de idiotas". 11 Por otra parte, es indudable su asociación con aquellas figuras que en conjunto he designado como hibridas o compuestas porque incorporan rasgos humanos, fantásticos y animales, y que previamente se han llamado "monstruos jaguares" o "felinos humanizados". Ahora bien, esa forma simbólica, la hendedura que en las hachas va en la frente de las figuras, y que parece ser parte de la cabeza misma de éstas, no corresponde a lo que se mira en las esculturas monumentales. En los Monumentos 10 y 52 de San Lorenzo y 64 de La Venta, el rostro queda claramente demarcado por una banda horizontal sobre la cual va un casquete seccionado por una hendedura central en forma de $V$; no se trata, por lo tanto, de la cabeza hendida sino, cuando más, del casquete hendido (figura 10). Hay otra modalidad en esta representación que se mira solamente en relieves -el niño más cercano a la parte posterior de la cara lateral derecha en el Altar 5 de La Venta y el Monumento 30 de San Lorenzo-; en ella la cabeza o un tocado muy bien ajustado a la misma, se proyecta hacia atrás y termina en la hendedura en forma de $V$. Variante de esta última es la cabeza del niño del "Señor de las Limas" en donde la $V$ hendida en la prolongación de la cabeza, se encuentra en eje con el entrecejo y no en vista de perfil.

De manera mucho más compleja y elaborada, como creo haber demostrado antes, se presenta la prolongación posterior y el corte en $\mathrm{V}$, visto

8 Saville, M. H. "Votive Axes from Ancient Mexico", parts 1 and 2. Indian Notes, vol. vi, pp. 266-299, 335-342, Museum of the American Indian, Heye Foundation, New York, 1929, p. 280.

Q Vaillant, G. C. "A Pre-Columbian Jade." Natural History, vol, 32, pp. 512-520, American Museum of Natural History. New York, 1932, p. 516.

10 Piña Chan, R. y L. Covarrubias. El pueblo del jaguar (los olmecas arqueológicos). Consejos para la planeación e instalación del Museo Nacional de Antropología. México, 1964, p. 37.

11 Coe, 1965: 752. 
desde distintos ángulos, en los tocados de los Monumentos 44 de La Venta y 1 de San Martín Pajapan, así como en este recién encontrado Monumento 77 (figura 5). Tengo para mí que tanto en los relieves como en el niño del "Señor de las Limas" y en los otros tres Monumentos citados, se pretendió la misma representación; no puede ser casual esa exagerada proyección del tocado o de la cabeza, sino que, con ella se está indicando algo significativo en cuanto a los atributos o características de este género de imágenes sobrenaturales.

Me parece, en fin, que si bien el símbolo de la $\mathrm{V}$ hendida, pudiera tener en todos los casos el mismo significado, su presencia adquiere, cuando menos, tres modalidades: el seccionamiento angular de la cabeza sobre el entrecejo, que corresponde a lo tradicionalmente designado como "cabeza hendida", y que se encuentra en la mayoría de las pequeñas hachas; el corte en ángulo del casquete o parte superior del tocado, que, aparte de en algunas hachas, se mira en las monumentales esculturas 10 y 52 de San Lorenzo y 64 de La Venta y, por último, la marcada prolongación hacia atrás de la cabeza o del tocado que culmina con su corte en $\mathrm{V}$ en los Monumentos previamente citados.

Además de los rasgos infantiles del rostro y el especial carácter de la parte posterior del tocado, quiero considerar otros dos elementos que no pueden carecer de interés en cuanto a lo que la figura representa. Me refiero a los cinco discos en cada una de las caras laterales del tocado, y a las prolongaciones aserradas que cuelgan de la banda cubriendo las orejas (figura 11). En cuanto a los primeros, los encuentro tan sólo en la fantástica figura de un artrópodo, Monumento 30 de San Lorenzo, dispuestos de manera simétrica; otra figura muy extraña, ya desaparecida, llamada por Coe "Jaguar-Dragón", 12 lleva el cuerpo cubierto de discos, y su número era mayor que los cinco del artrópodo y del Monumento 76 de La Venta. Por su parte, Joralemon registró el mismo diseño de cinco puntos en fragmentos cerámicos procedentes de Tlapacoya. ${ }^{13}$ Su carácter simbólico me parece irrefutable. En lo que respecta a las prolongaciones aserradas, son análogas a las del Monumento 52 de San Lorenzo y, guardando la proporción, a las del niño del "Señor de las Limas", se encuentran también en algunas figuras menores que participan indistintamente de algunos de los rasgos antes

12 Coe, M. D. "La segunda temporada en San Lorenzo Tenochtitlan, Veracruz." Boletin del Instituto Nacional de Antropologia e Historia, núm. 28, Pp. 1.10. México, 1967, p. 10.

13 Joralemon, 1971: 17. 
mencionados, a saber: bandas cruzadas, hendedura en $V$, e inclusive rasgos humanos infantiles.

No me inclino, como otros autores, por adjudicar identidades propias de dioses del panteón azteca a las remotisimas imágenes del mun. do olmeca. Muchos son los siglos que median entre una y otra cultura para que se deba suponer, que aunque en sus origenes, se trata de signos y de significados semejantes. Me he limitado a señalar algunos rasgos que concurren en una misma imagen, en el Monumento 77 de La Venta, y he procurado compararlos con los de otras esculturas monumentales con el objeto de integrar un conjunto de imágenes que, tal vez, sean portadoras del mismo significado esencial. Creo, en suma, que en él se trata de la misma entidad que figuran el idolo de San Martín Pajapan y el Monumento 44 de La Venta, con la particularidad, ya lo dije, de que en este Monumento 77, los atributos simbólicos que denotan su cualidad, se han sintetizado a sus rasgos más indispensables (figura 1). Por otra parte, tiene también una evidente cercanía, en cuanto a la naturaleza de su significado, con el niño del "Señor de las Limas".

Los elementos diagnósticos para procurar la identidad del Monumento 77, se encuentran en el rostro de aspecto humano-infantil, carente de individualidad; el tocado al cual probablemente falta una máscara de rasgos humano-felinos al frente, y que se prolonga hacia atrás para rematar en una doble bifurcación; los cinco discos en las caras laterales del tocado; los colgantes aserrados que descienden del tocado, cubriendo las orejas, y el pectoral y el ceñidor de bandas cruzadas. Otros rasgos secundarios que deben de contribuir a denotar el carácter de la figura, son la capa con su diseño simbólico; el elemento, casi irreconocible, sobrepuesto al cabello en el centro de la espalda, y el remate que se proyecta al frente sobre la banda del tocado.

Ahora bien, al observar cuidadosamente las esculturas olmecas se aprecian dos características fundamentales. La primera, que por su constancia me parece la más importante, es que, aun cuando las imágenes oscilan entre dos maneras casi extremas de representación, una más fantástica y alejada de la realidad visual y la otra más acorde con la naturaleza, en ellas predomina siempre la representación de la figura humana. No ocurre, y dejo constancia de lo observado en la escultura monumental, que la imagen más frecuente sea la del felino humanizado, también llamado were-jaguar sino que todas las figuras, con excepción 
de las poquísimas estrictamente animales, comparten una estructura esencialmente humana.

La otra característica que encuentro, es que los rasgos o atributos simbólicos que denotan la identidad de las imágenes, no son exclusivos de una sola o de un conjunto de ellas, sino que se intercambian o aparecen en diferentes contextos visuales. De lo anterior se desprende la dificultad de agruparlas con base en elementos iconográficos similares. Los intentos por formar conjuntos de figuras, de acuerdo con este método, si bien representan un avance en el conocimiento de los elementos utilizados en la plástica olmeca, no trascienden un nivel preiconográfico. ${ }^{14}$

Más remota me parece aún la posibilidad de adjudicar a ciertas imágenes olmecas no sólo su plena idlentidad sino las propiedades de su ser particular. Así, que me resulta inaceptable y en ello difiero de Coe 15 y 18 y Joralemon, ${ }^{17}$ :18 el reconocimiento de deidades específicas. La falta de documentos escritos de esta época remotísima y la discontinuidad en el conocimiento de las culturas prehispánicas impiden, por ahora, identificaciones precisas. No pretendo abundar con hipótesis en torno a la identidad de los dioses olmecas, sino aproximarme más bien a la comprensión de los significados intrínsecos que las imágenes representan.

El Monumento 77 representa una figura compuesta que combina rasgos humano-infantiles con atributos simbólicos que pueden, acaso, tener relación con el jaguar; su aspecto resulta fantástico ya que no sigue un modelo de la naturaleza. Imágenes como ésta, que incorporan a su aspecto esencialmente humano rasgos felinos e imaginados, representan a seres sobrenaturales. Son criaturas que no existen en la realidad, a diferencia de aquellas representadas por los mismos olmecas en las cabezas colosales, y su carácter híbrido puede ser considerado como apareamiento de símbolos. En ellas se concentra una carga cósmico-vital ambivalente, arraigada en la relación emocional entre los hombres y las manifestaciones animadas de los elementos de la naturaleza. No son, a mi modo de ver, representaciones de dioses particulares sino personificaciones de fuerzas; son conceptos que se figuran relevados de las leyes ordinarias de lo real.

14 lbid.

15 Coe, 1968.

16 Coe, 1971.

17 Joralemon, 1971.

18 Joralemon, D. The Olmec Dragon. A Study in Pre-Columbian Iconography. Yale University (faltan datos). 
Las imágenes-concepto son lo primordial, el prototipo, el modelo original; guardan significaciones esenciales relativas a las experiencias básicas de la vida y de la muerte, a las fuerzas de la naturaleza y a la magnitud del cosmos. Está en ellas subyacente la imagen en que el hombre tenía de sí mismo, y de su situación respecto a la naturaleza terrenal y cósmica, de la cual dependía a la vez que dominaba. Las imágenesconcepto se muestran como figuras humanas, pero encierran contenidos tales como mitos de creación, de renovación y fertilidad así como de sacrificio y de salvación. Son como un puente entre las imágenes de aspecto estrictamente humano, y las otras que evocan con formas más concretas los mitos primordiales.

El Monumento 77 de La Venta revela una formidable adecuación de las formas plásticas, regidas por los principios de la proporción armónica, con un contenido de importancia principal; por eso su relevancia como obra de arte. Su estilo innegablemente olmeca la emparienta, en su aspecto formal, con ciertas esculturas de San Lorenzo - Monumentos 47 y $11-$, en tanto que en su significación está más cercana de otros monumentos - Monumento I de San Martín Pajapan, Monumento 44 de La Venta, y niño del Monumento 1 de Las Limas. Al considerar la totalidad de las esculturas olmecas monumentales, es posible suponer que la imagen sagrada representada en el Monumento 77 se gestó en San Lorenzo, pienso concretamente en los Monumentos 10, 52 y 47, de este sitio, pero tuvo una mayor aceptación en La Venta - Monumento 44y en otros lugares - San Martín Pajapan y las Limas-, en cuyas esculturas se aprecia una cercana relación estilística con ellas. El Monumento 77 de La Venta incrementa nuestro conocimiento del patrimonio escultórico que los olmecas nos legaron; imagen humana en piedra, a la cual se confió la preservación de conceptos primordiales. 